\title{
Voltage instability analysis based on modal analysis technique and artificial neural network
}

\author{
Ahmad Fateh Mohamad Nor', Marizan Sulaiman² \\ ${ }^{1}$ Green and Sustainable Energy (GSEnergy) Focus Group, Department of Electrical Power Engineering, \\ Faculty of Electrical and Electronic Engineering, Universiti Tun Hussein Onn Malaysia, Malaysia \\ ${ }^{2}$ Center for Robotics and Industrial Automation, Faculty of Electrical Engineering, \\ Universiti Teknikal Malaysia Melaka, Malaysia
}

\begin{tabular}{|c|c|}
\hline Article Info & ABSTRACT \\
\hline Article history: & \multirow{10}{*}{$\begin{array}{l}\text { One of the paramount importance in the operation of electrical power system } \\
\text { operation order to sustain the equilibrium of the system is the stability of the } \\
\text { load buses' voltages. If the load buses voltages are not stable, this can cause } \\
\text { serious problem especially power system blackout. This paper presents the } \\
\text { analysis of voltage instability in electric power system by using modal } \\
\text { analysis technique. However, one of the challenges of modal analysis is the } \\
\text { intencive and complex calculation procedures. In order to overcome that, this } \\
\text { paper implements Artificial Neural Network (ANN) to improve the } \\
\text { implementation of modal analysis technique. ANN is used to determine the } \\
\text { participation factors obtained from the modal analysis technique. The results } \\
\text { show that modal analysis technique is able to show which bus is close } \\
\text { towards experiencing voltage instability. In addition, the results also show } \\
\text { that ANN is able to predict the values of participation factors. A load bus is } \\
\text { considered a weak bus if the bus has high tendency towards experiencing } \\
\text { voltage instability. IEEE-14 bus test power system has been chosen as the } \\
\text { test power system. }\end{array}$} \\
\hline Received Sep 30, 2018 & \\
\hline Revised Dec 22, 2018 & \\
\hline Accepted Jan 2, 2019 & \\
\hline Keywords: & \\
\hline ANN & \\
\hline IEEE-14 bus test system & \\
\hline MATLAB & \\
\hline Modal analysis technique & \\
\hline Voltage instability analysis & \\
\hline
\end{tabular}

Copyright $\odot 2019$ Institute of Advanced Engineering and Science. All rights reserved.

\section{Corresponding Author:}

Ahmad Fateh Mohamad Nor,

Green and Sustainable Energy (GSEnergy) Focus Group,

Department of Electrical Power Engineering, Faculty of Electrical and Electronic Engineering,

Universiti Tun Hussein Onn Malaysia,

86400 Parit Raja, Batu Pahat, Johor, Malaysia.

Email: afateh@uthm.edu.my

\section{INTRODUCTION}

Electrical power blackout has always been a major problem not only to the electrical power engineers, but also to the consumers. Power system blackouts will give massive effect not only to the operation of the electrical power system, but also to the day to day business that can lead to much worse problems such as economic losses. It has been found out that most of the electrical power blackouts that occurred at most part of the world were caused by voltage instability [1]-[3]. Voltage instability will take place due to the failure of the electrical power system to maintain the bus voltages remain the same after the electrical power system is being subjected to a disturbance [4]-[5]. For every operation of electrical power system, it is very important that the system operates within the allowable voltage range and as far as possible from the voltage critical point. If the power system reaches the voltage critical point, the voltage system will enter unstable region and hence, lead to blackout. However, due to the rapid development that occurred all over the world especially in developing countries, has resulted in the increasing of electricity load demand per year [6]. The incremental value of load demand especially reactive power (Q) load demand will make the electrical power system to operate close to the voltage instability limit [7]. This is where the importance of analysing voltage instability take place. Voltage instability analysis is very important in order to make sure 
that the load buses in the power system operate within the allowable voltage range. A load bus is considered as a weak bus if it operates near the voltage critical point. Modal analysis technique is very useful to determine the weak load buses [8]. In modal analysis technique, the load bus participation factor is identified. The load bus with the highest participation factor is the weakest bus in the system and vice-versa. However, the modal analysis technique involes very detail and intensive measures and calculations such as the determination of reduced Jacobian matrices, determination of eiganvalues etc. To overcome this, this research will apply Artificial Neural Network (ANN) in the modal analysis technique. ANN will be used to determine the value of the load buses participation factors.

\section{RESEARCH METHOD}

\subsection{Modal Analysis Technique}

The modal analysis technique was introduced by Gao, Morisson and Kundur in 1992 [9]. This technique intends to determine the participation factors of the load buses. The participation factors can be determined from the values of eigenvalue and eigenvector of the reduced Jacobian matrix. The higher the value of participation factor, the closer the load buses towards experiencing voltage instability. The procedures of the modal analysis technique are explained as follows:

\subsubsection{Reduced Jacobian Matrix (Jr)}

The first step in the modal analysis technique the determination of the reduced Jacobian Matrix (Jr). The Jacobian matrix that is obtainable form the Newton Raphson power flow method represents the injected real power (P) and reactive power (Q). The relationship is shown in Equation (1) [2], [10], [11].

$$
\left[\begin{array}{l}
\Delta P \\
\Delta Q
\end{array}\right]=\left[\begin{array}{ll}
J_{P \delta} & J_{P V} \\
J_{Q \delta} & J_{Q V}
\end{array}\right]\left[\begin{array}{l}
\Delta \delta \\
\Delta V
\end{array}\right]
$$

where

$\Delta P$ is the incremental change in bus real power

$\Delta Q$ is the incremental change in bus reactive power

$\Delta \delta$ is the incremental change in bus voltage angle

$\Delta V$ is the incremental change in bus voltage magnitude

In order to identify the reduced Jacobian matrix ( $\mathrm{Jr})$, the value of $\Delta P$ is being substitute with 0 . Equation (2) explains it.

$$
\left[\begin{array}{c}
0 \\
\Delta Q
\end{array}\right]=\left[\begin{array}{cc}
J_{P \delta} & J_{P V} \\
J_{Q \delta} & J_{Q V}
\end{array}\right]\left[\begin{array}{c}
\Delta \delta \\
\Delta V
\end{array}\right]
$$

From Equation (2), the following Equation (3) and Equation (4) can be obtained.

$$
\begin{aligned}
& \Delta \delta=-J_{P \delta}{ }^{-1} J_{P V} \Delta V \\
& \Delta Q=J_{Q \delta} \Delta \delta+J_{Q V} \Delta V
\end{aligned}
$$

Equation (5) below is formed by substituting Equation (3) into Equation (4)

$$
\Delta Q=\Delta V\left[J_{Q V}-J_{Q \delta} J_{P \delta}^{-1} J_{P V}\right] \text { or } \Delta Q=J_{r} \Delta V
$$

where $J_{r}=\left[J_{Q V}-J_{Q \delta} J_{P \delta}{ }^{-1} J_{P V}\right]$. Equation (6) is formed by reorganizing Equation (5).

$$
\Delta V=J_{r}^{-1} \Delta Q
$$

Equation (6) shows the relationship between the incremental changes of voltage and reactive power. This proofs that the incremental value of reactive power will affect the value of voltages.

\subsubsection{Determination of the Most Critical Mode}

The second step in modal analysis is the determination of the most critical mode. The eigenvalues and eigenvectors of $J_{r}$ can be used to determine the modes of the power network. The lowest value of eigenvalue of $J_{r}$ determines the most critical mode of the power system [9], [12], [13]. Equation (7) depicts their relationship [2], [9]-[11]. 


$$
J_{r}=\xi \Delta \eta
$$

where

$\xi$ is the right eigenvector of $J_{r}$

$\Delta$ is the diagonal eigenvalue of $J_{r}$

$\eta$ is the left eigenvector of $J_{r}$

\subsubsection{Determination of the Participation Factor}

The final and main procedure of the modal analysis technique is the determination of the participation factors of the load buses. The bus participation factor is an indicator that shows the tendency of a particular bus towards voltage instability. It should be calculated at the bus that has the most critical mode. The bus participation factor is calculated by using Equation (8) [9],[11],[13].

$$
P k_{i}=\xi_{i} \eta_{i}
$$

where

$P k_{i}$ is the participation factor of bus $\mathrm{k}$ to mode $i$

$\xi_{i}$ s the $i^{\mathrm{h}}$ column right eigenvector of $J_{r}$

$\eta_{i}$ is the $\mathrm{i}^{\text {th }}$ row of left eigenvector of $J_{r}$

In addition, the bus participation factor obtained from Equation (8) is shown in matrix form. The row of the matrix indicates the number of the bus. The column of the matrix shows the mode of the power network. The larger the value of bus participation factor of a bus, the closer the bus towards voltage instability and vice versa.

\subsection{Application of Artificial Neural Network (ANN)}

In this research, ANN will be used to predict the value of participation factor that has been determined from Sub-section 2.1. In order to achieve that, the ANN model must be trained to learn the relationship between the input quantities and the output [14]. For this purpose, approximately 500 training data were generated. The multilayer perceptron with backpropagation (MLPBP) ANN model is the most widely used of ANN model [15],[16]. In this research the MLPBP ANN model will be optimized in order to predict the participation factors. The inputs of the optimized MLPBP ANN are the vslues of real and reactive power of loads (P and Q loads).

Figure 1 depicts the configuration MLPBP ANN network that is being made up of input layer ( $\mathrm{P}$ and $\mathrm{Q}$ load in per unit), hidden layer and the output layer (values of participation factors). The prediction output values will then be being compared with the participation factors determined in Sub-section 2.1 in order to find the errors. The error is important in order to improve the ANN's predictions values. MATLAB Neural Network Toolbox is used to run the optimized ANN model. The optimized ANN model in MATLAB is shown in Figure 2. In this research, the numbers of neuron in the hidden layer is 10 which is the default value in toolbox.

\subsection{IEEE 14-bus System}

The IEEE 14-bus system has been chosen as the test power system this paper. The modal analysis technique will be applied upon this test power system. IEEE 14-bus test power system consists of one slack bus (Bus 1), four voltage controlled buses (Bus 2, Bus 3, Bus 6 and Bus 8) and nine load buses (Bus 4, Bus 5, Bus 7 and Bus 9 until Bus 14) [17]. Figure 3 [17]-[20] depicts the diagram of this test power system.

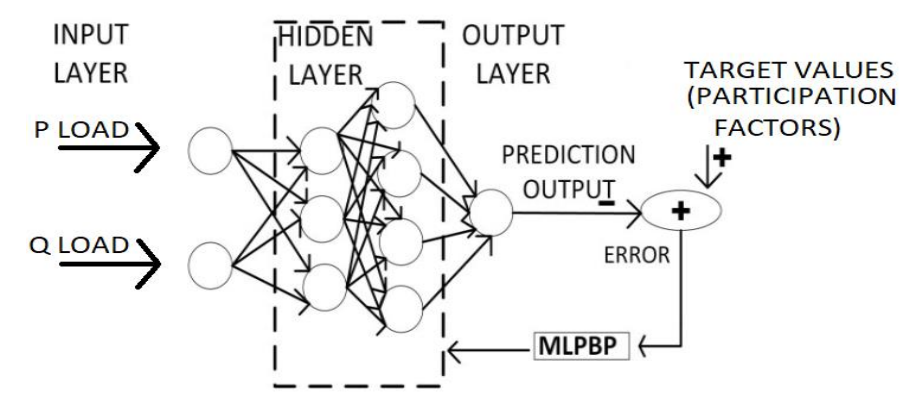

Figure 1. Configuration of the MLPBP ANN network 


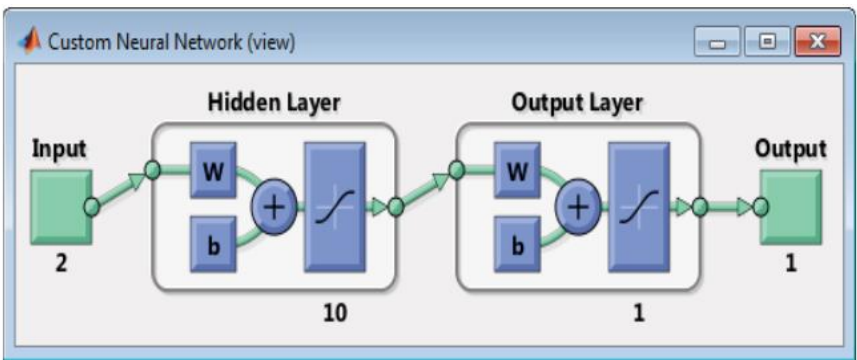

Figure 2. Configuration of ANN model in MATLAB

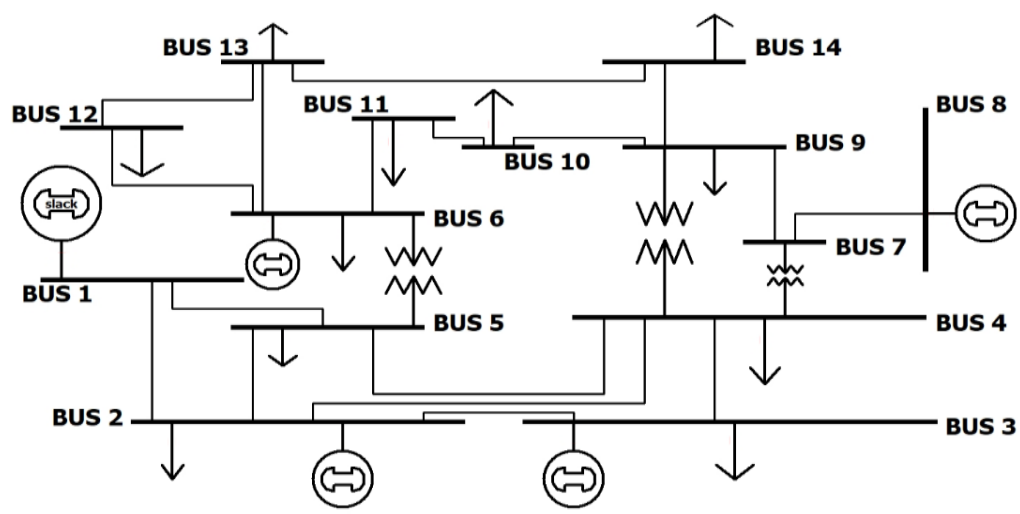

Figure 3. IEEE 14-Bus Test Power System

\section{RESULTS AND ANALYSIS}

\subsection{Modal analysis result}

In this section, the results obtained from performing the modal analysis technique on the test bus system are presented in Figure 4.

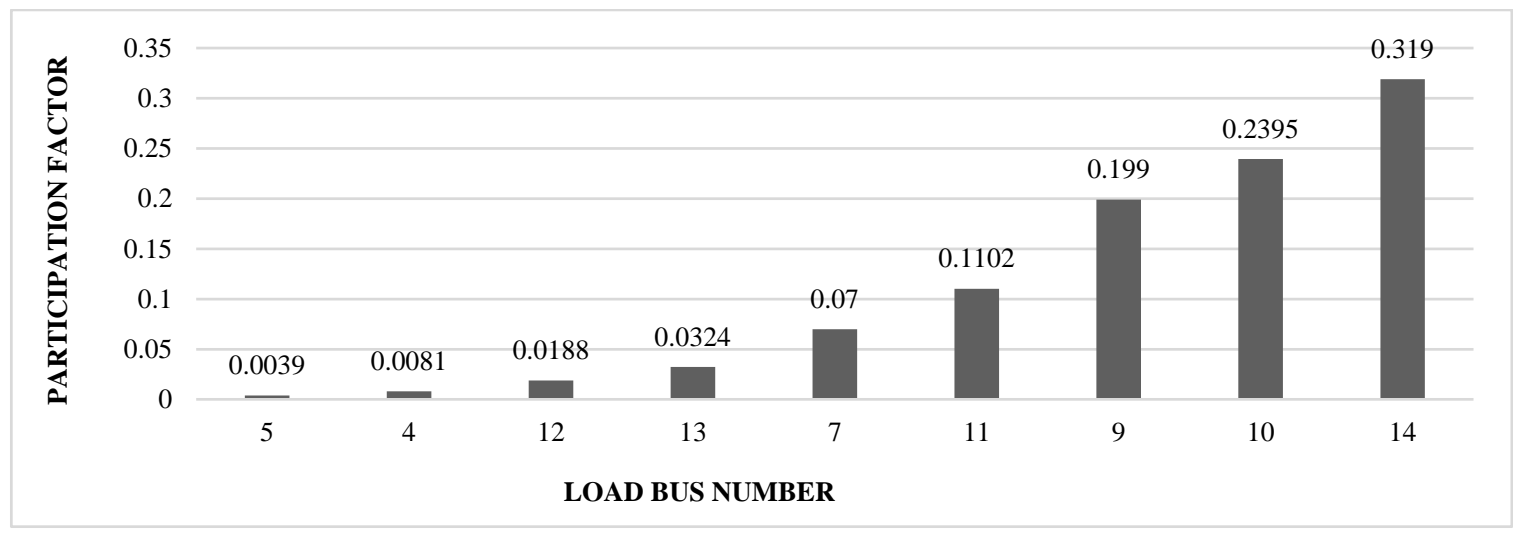

Figure 4. Participation Factors for The IEEE 14-Bus Power System

As can be seen in Figure 4, Bus 14, Bus 10 and Bus 9 have high participation factor with Bus 14 is the highest which is 0.3190 . This means that Bus 14 has the highest tendency towards voltage instability. One more important information that can be learned from Figure 4 is that Bus 5 and Bus 4 are the two most stable load buses in this power system. It is also noticeable from the results presented in Figure 4 that only the load buses that possess the participation factor. This is because this modal analysis technique focuses on the relationship between the incremental changes of voltage and reactive power as stated in Equation (6). Since 
the voltages of the slack and voltage-controlled buses are fixed prior to the load flow analysis, no participation factor is available on these buses.

\subsection{Prediction of Participation Factors by ANN}

In this paper, ANN is used to determine the participation factors as shown in Figure 4. The participation factors from both methods were compared and analysed. Figure 5 depicts the participation factors obtained from ANN and the comparison with the data in Figure 4.

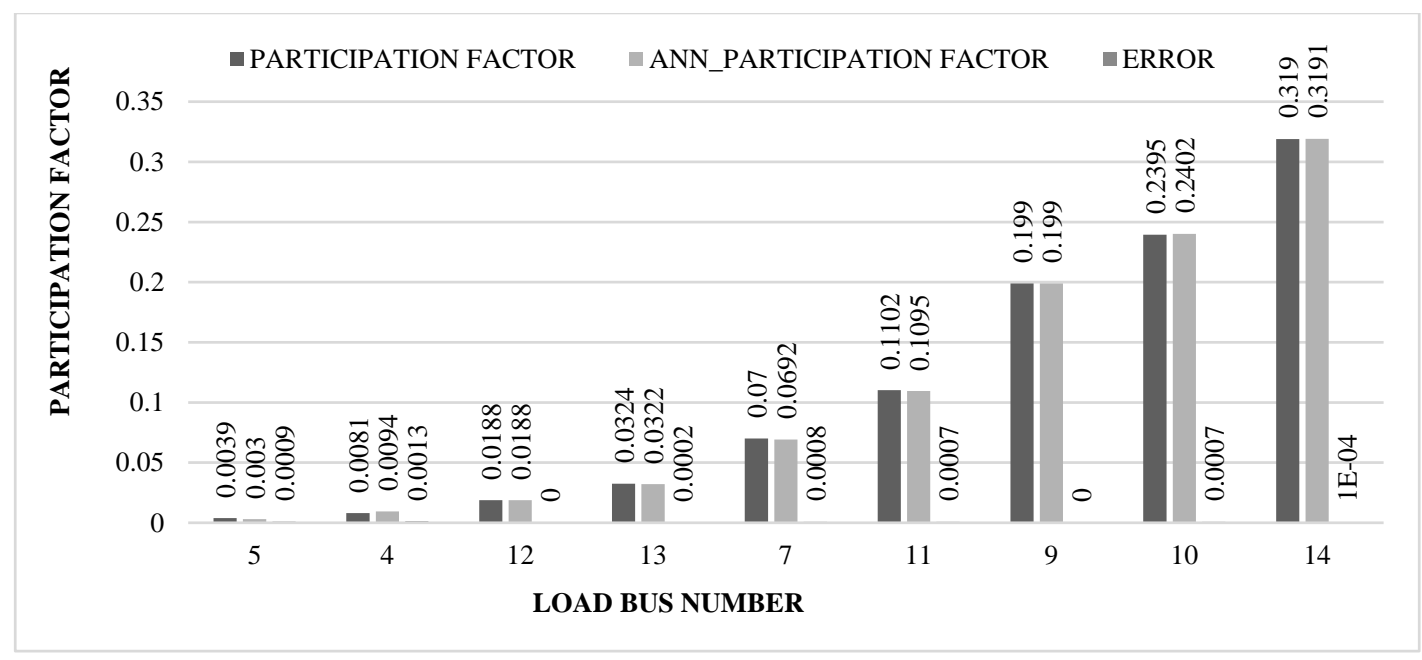

Figure 5. Participation Factors Obtained from ANN and the Comparison with The Data in Figure 4

As can be seen in Figure 5, ANN has the ability to predict the participation factors close to the participation factor in Figure 4. The 'error' in Figure 5 is the difference (absolute value) between the participation factor in Figure 4 with the values predicted from ANN. The highest value of error is only 0.0009 recorded at Bus 5. This shows that this configuration of ANN can be used to predict the participation factors and hence, help in improving the voltage instability modal analysis technique.

\section{CONCLUSION}

The research has shown the importance of analyzing voltage instability in electric power system. The modal analysis technique is very valuable in determining which load bus is prone towards experiencing voltage instability. The results have also shown that ANN has the ability to predict load buses participation factors that can be used for determining weak buses. Once the weak load buses is determined, the engineers and power system planners can use the information to plan and manage the increased of load demand properly in order to avoid voltage instability from taking place. Voltage instability must be avoided from taking place because the consequences of voltage instability are fatal. The power systems blackouts that are caused by voltage instability might spread to the entire country. Aside from power distribution problems, the power systems blackouts that are caused by voltage instability will cause much worse such as economic losses. It is suggested in future research to consider the affect of distributed generator such as solar panels or wind turbine towards the stability of the voltage.

\section{ACKNOWLEDGEMENTS}

The authors are grateful to the Faculty of Electrical and Electronic Engineering, Research Management Centre of Universiti Tun Hussein Onn Malaysia (UTHM) for the support and beneficial research platform.

\section{REFERENCES}

[1] A. F. M. Nor, et al., "Voltage Instability Analysis for Electrical Power System Using Voltage Stabilty Margin and Modal Analysis," Indonesian Journal of Electrical Engineering and Computer Science, 3(3), pp. 655-62, 2016. 
[2] Mobarak Y. A., "Voltage Collapse Prediction for Egyptian Interconnected Electrical Grid EIEG," International Journal on Electrical Engineering and Informatics, vol/issue: 7(1), pp. 79-88, 2015.

[3] Poornazaryan B., et al., "Optimal Allocation and Sizing of DG Units Considering Voltage Stability, Losses and Load Variations," International Journal of Electrical Power and Energy Systems, vol. 79, pp. 42-52, 2016.

[4] A. F. M Nor., et al., "Voltage Stability Analysis of Load Buses in Electric Power System Using Adaptive Neurofuzzy Inference System (ANFIS) and Probabilistic Neural Network (PNN)," ARPN Journal of Engineering and Applied Sciences, vol/issue: 12(5), pp. 1406-10, 2017.

[5] A. F. M. Nor and M. Sulaiman. "Comparison of ANFIS and ANN-BP Approaches in Voltage Stability Analysis of Load Buses in Electric Power System," International Journal of Electrical and Computer Engineering (IJECE), 2017.

[6] Rahmat N. A., et al., "Optimizing Economic Load Dispatch with Renewable Energy Sources via Differential Evolution Immunized Ant Colony Optimization Technique," International Journal on Advanced Science, Engineering and Information Technology, vol/issue: 7(6), pp. 2012-7, 2017.

[7] Perez-Londono S. M., et al., "Online Determination of Voltage Stability Weak Areas for Situational Awareness Improvement," Electric Power Systems Research, vol. 145, pp. 112-21, 2017.

[8] A. F. M. Nor and M. Sulaiman, "Voltage Stability Assessment of Power System Network using QV and PV Modal Analysis," Journal of Telecommunication, Electronic and Computer Engineering (JTEC), vol/issue: 8(7), pp. 7-11, 2016.

[9] Gao B., et al., "Voltage Stability Evaluation using Modal Analysis," IEEE Transactions on Power Systems, vol/issue: 7(4), pp. 1529-42, 1992.

[10] Saadat H., "Power System Analysis," Singapore, McGraw-Hill Inc., 2004.

[11] Telang B. and Khampariya P., "Voltage Stability Evaluation Using Modal Analysis," International Journal of Scientific Research Engineering \& Technology (IJSRET), vol/issue: 4(4), pp. 408-11, 2015.

[12] Sharma C. and Ganness M. G., "Determination of the Applicability of using Modal Analysis for the Prediction of Voltage Stability," Transmission and Distribution Conference and Exposition, Chicago, IEEE, pp. 1-7, 2008.

[13] Enemuoh F. O., et al., "Modal Based Analysis and Evaluation of Voltage Stability of Bulk Power System," International Journal of Engineering Research and Development, vol/issue: 6(12), pp. 71-9, 2013.

[14] A. F. M Nor, et al.,"Study of Voltage and Power Stability Margins of Electrical Power System Using ANN," IET Conference Publications. Kuala Lumpur, pp. 1-7, 2016.

[15] Zhou D. Q., et al., "Online Monitoring of Voltage Stability Margin Using an Artificial Neural Network," IEEE Transactions on Power Systems, vol/isue: 25(3), pp, 1566-74, 2010.

[16] Goh H. H., et al., "Evaluation for Voltage Stability Indices in Power System Using Artificial Neural Network," Procedia Engineering. Elsevier B.V., pp. 1127-36, 2015.

[17] Pai M. A.. "Computer Techniques in Power System Analysis,” New Delhi, Tata McGraw-Hill, 2006.

[18] Pai M. A., "Energy Function Analysis for Power System Stability,” Dordrecht, Kluwer Academic Publishers, 1989.

[19] Chen N., et al., "Electric Vehicle Charging in Smart Grid: Optimality and Valley-Filling Algorithms," IEEE Journal of Selected Topics in Signal Processing, vol/issue: 8(6), pp. 1073-83, 2014.

[20] Choi D. and Xie L., "Data Perturbation-Based Sensitivity Analysis of," IEEE Transactions on Power Systems, vol/issue: 32(3), pp. 2072-82, 2017.

\section{BIOGRAPHIES OF AUTHORS}

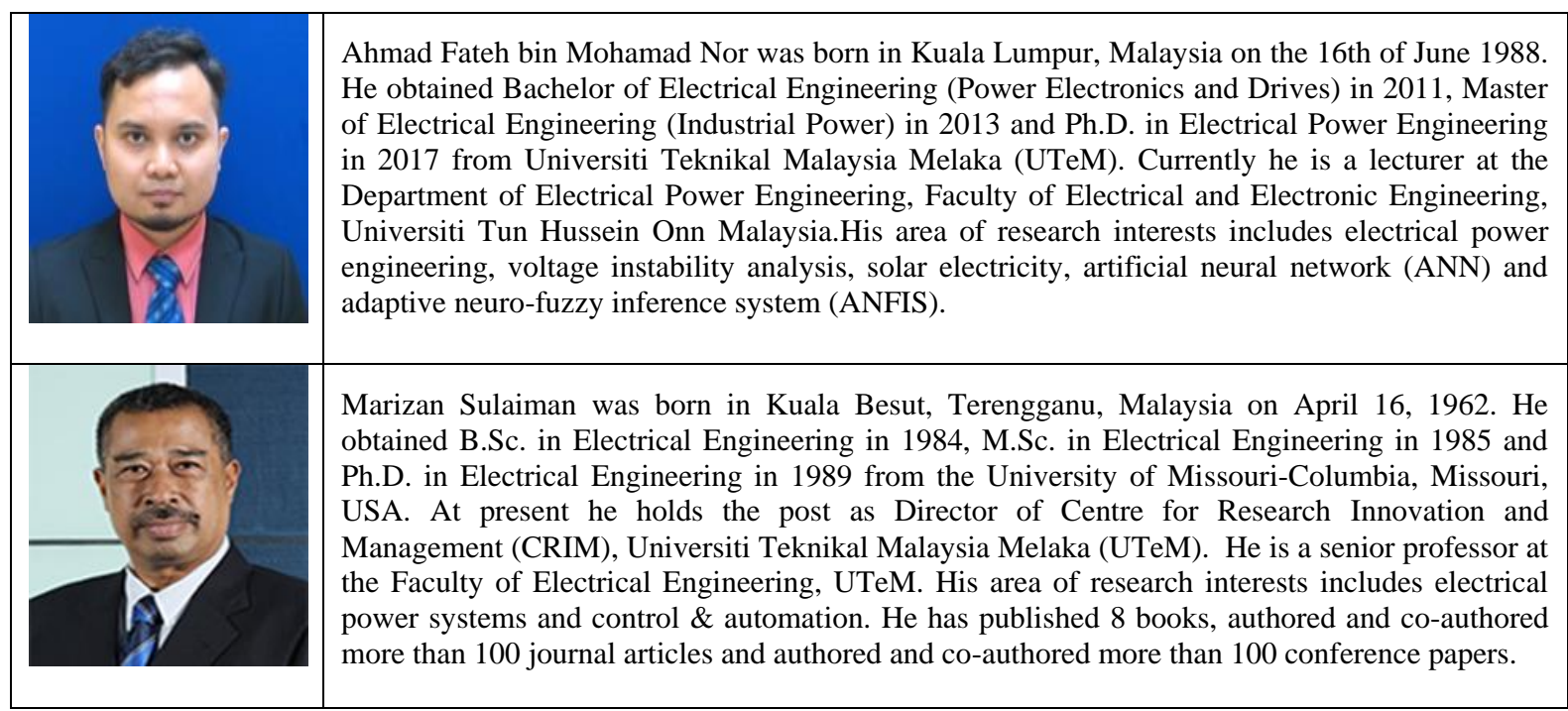

